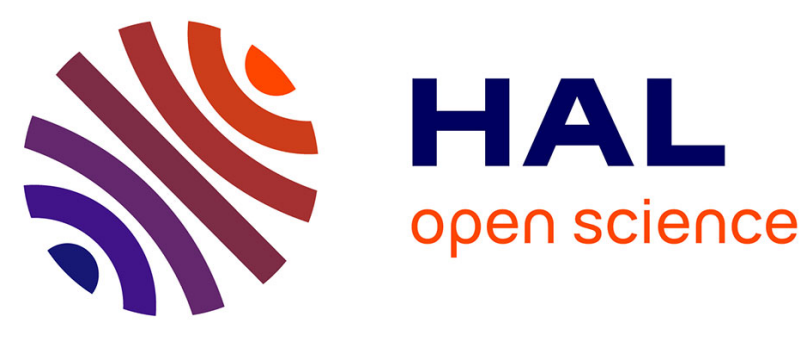

\title{
Limiting discharge cycles numbers for plug-in electric vehicles in bidirectional smart charging algorithm
}

Reza Razi, Khaled Hajar, Majid Mehrasa, Antoine Labonne, Ahmad Hably, Seddik Bacha

\section{- To cite this version:}

Reza Razi, Khaled Hajar, Majid Mehrasa, Antoine Labonne, Ahmad Hably, et al.. Limiting discharge cycles numbers for plug-in electric vehicles in bidirectional smart charging algorithm. IECON 2021 47th Annual Conference of the IEEE Industrial Electronics Society (IES), Oct 2021, Toronto (virtual ), Canada. 10.1109/IECON48115.2021.9589844 . hal-03410199

\section{HAL Id: hal-03410199 \\ https://hal.science/hal-03410199}

Submitted on 4 Oct 2022

HAL is a multi-disciplinary open access archive for the deposit and dissemination of scientific research documents, whether they are published or not. The documents may come from teaching and research institutions in France or abroad, or from public or private research centers.
L'archive ouverte pluridisciplinaire HAL, est destinée au dépôt et à la diffusion de documents scientifiques de niveau recherche, publiés ou non, émanant des établissements d'enseignement et de recherche français ou étrangers, des laboratoires publics ou privés. 


\title{
Limiting discharge cycles numbers for plug-in electric vehicles in bidirectional smart charging algorithm
}

\author{
Reza Razi $^{1}$, Khaled Hajar', Majid Mehrasa², Antoine Labonne ${ }^{2}$, Ahmad Hably', Seddik Bacha² \\ ${ }^{1}$ Univ. Grenoble Alpes, CNRS, Grenoble INP*, GIPSA-Lab, 38000 Grenoble, France \\ ${ }^{2}$ Univ. Grenoble Alpes, CNRS, Grenoble INP*, G2ELAB, 38000 Grenoble, France \\ *Institute of Engineering Univ. Grenoble Alpes
}

\begin{abstract}
This is a fact that the battery life is inversely related to the number of discharge cycles. However, these days, the bidirectional smart charging scenario of plug-in electric vehicles (PEVs) has become a hot trend, using them as a storage source at peak load or price. Therefore, this paper aims to present a simple and novel technique in predictive-based linear programming for limiting the number of discharge cycles of PEV. In this regard, a specified number of cycles is defined by the user such that the predictive algorithm tries to use these cycles in the most optimal way. In this paper, first, the effect of the discharging cycle on the battery life available in the literature is presented. Then, the photovoltaic-assisted charging station configuration and desired optimization algorithm are introduced. Following, the main novelty of this work, i.e. a linear technique for limiting the number of discharging cycles will be described. Finally, the simulation results are provided to validate the performance of the proposed method.
\end{abstract}

Keywords-Battery degradation, Discharge cycles, Model predictive control, Plug-in electric vehicles, Smart charging.

\section{INTRODUCTION}

In recent years, the share of PEVs is growing rapidly in the automotive industry [1]. PEVs represent the two main categories of battery electric vehicles (BEVs) and plug-in hybrid electric vehicles (PHEVs). In the typical structure of these vehicles, electric motors are used for propulsion that are powered by the energy stored in their batteries. Also, to fully charge the batteries, PEVs need to be connected to a power outlet. In this regard, the battery plays a key role in these vehicles and therefore, one of the main challenges in replacing PEVs with conventional vehicles powered by fossil fuels is the battery and its health status [2].

On the other hand, besides the usual duty of batteries in charging mode and feeding electric motors, they can also be used as energy storage sources when PEVs are parked. In fact, due to the planning of energy demand growth and control of charging and discharging modes of electric vehicles, the cooperation of renewable energy sources and PEVs, known as smart charging, has been become a hot trend recently [3]-[5]. In other words, the power generation of photovoltaic arrays is usually at its highest level around noon, while the energy demand of PEVs has two peaks, morning and afternoon. Some users charge their car in the morning after arriving at the workplace, and many of them are convenient for charging in the evening when they arrive at home, which often coincides with the daily load peak. As a result of the lack of coordination between these two emerging technologies, the load curve is far from a flat position more than before [6], [7]. Therefore, in recent studies, it has been tried to charge the vehicle's battery with solar power or employ its ability to store energy and use it during peak times or high prices. In simple terms, PV power generation is saved in the battery when the load or price is somewhat low such that be used at other times. However, excessive use of batteries will damage their health in several cases, which are described in [8]-[11] in detail.

Given the aforementioned issues, this paper intends to develop a simple and novel technique to limit the number of discharge cycles. In this regard, the linear optimization approach based on model predictive control (MPC) is employed as a conventional method for smart charging of PEVs. Therefore, the proposed technique should have this capability to be implemented as a linear constraint so that can be added to the linear programming method.

The rest of the paper is organized as follows: Section II describes a typical configuration of a PEV charging station briefly. Section III introduces the bidirectional smart charging algorithm. Section IV explains the proposed linear technique for limiting discharge cycle numbers. Finally, Sections V and VI present the simulation results and conclusion of this paper.

\section{CONFIGURATION OF CHARGING STATION}

First of all, it is necessary to introduce the common configuration of a PEV charging station and the role of various elements in it. In this paper, the desired structure is shown in Fig. 1, which consists of the utility grid, local loads, solar arrays, and PEVs. As mentioned, in the structures used recently, the use of renewable energies, especially solar energy, is inevitable.

In the first place, due to the low incremental cost, the system controller tries to harvest the maximum possible power from the PV arrays by means of the maximum power point tracking (MPPT) technique. It should be noted that uncertainties and power fluctuations in photovoltaic arrays make challenges in power management optimization. In this regard, several approaches have been proposed to accurately predict PV production capacity [12]. Here, it is assumed that solar arrays are present with a maximum power of $14 \mathrm{~kW}$ and their output power during a whole day is estimated according to Fig. 2 (a). 


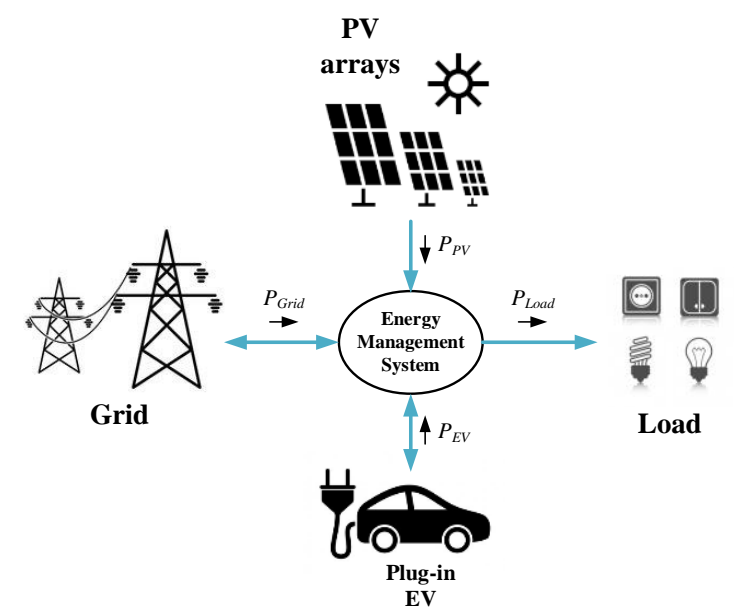

Fig. 1. Desired configuration of charging station.

TABLE I

PEV SPECIFICATION DETAILS

\begin{tabular}{|c|c|c|}
\hline Symbol & Description & Value \\
\hline$P_{P E V}^{\max / \min }$ & Maximum/minimum PEV power & $22 /-22 \mathrm{~kW}$ \\
\hline$E_{P E V}^{n o m}$ & Nominal capacity of PEV battery & $41 \mathrm{kWh}$ \\
\hline$S O C_{P E V}^{\max / \min }$ & $\begin{array}{c}\text { Maximum/minimum PEV State of } \\
\text { charge (SOC) }\end{array}$ & $90 \% / 20 \%$ \\
\hline$P_{C h}^{\max / \min }$ & Maximum/minimum charger power & $15 /-15 \mathrm{~kW}$ \\
\hline
\end{tabular}

On the other side of the configuration under study, there are typical local loads with different and time-variable power demands, depending on the location of the charging station in residential buildings, workplaces, or private and public parking lots. Assuming the charging station in a residential building, as shown in Fig. 2 (b), the load demand is close to zero in the early hours of the day, while it has the highest values in the early hours of the night. It should be noted that load demand, like power generation in solar arrays, has uncertainties that are estimated by appropriate algorithms. In the usual structure, the load demand needs to be fully met by the production components.

Before going to the next component i.e. PEV and describing its impact on the system structure, it is better to clarify the role of the utility grid. According to the general procedure, in this structure, the grid as the dominant element is responsible for power balancing among different elements in such a way as to compensate for the excess or lack of generated power according to Equation (1).

$$
P_{\text {Grid }}=P_{\text {Load }}-P_{E V}-P_{P V}
$$

This equation is known as the power balance equation, where its variables signs are considered with respect to the power directions assumed in Fig. 1. In other words, if the total power production is less than the power consumption, the power difference is injected into the system by the grid. Generally, the main purpose of scheduling methods is to reduce the cost of energy exchanged with the grid. In reality, however, the electricity price is highly variable and unbalanced in the wholesale market, while the approved price for residential users typically has two or three different levels. For example, the electricity price for home users in France is 13.46 and 17.99 cents per kilowatt-hour, respectively, during normal and peak hours [13]. In this paper, to simplify and

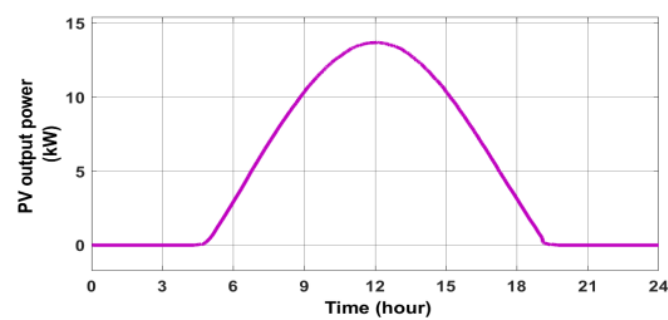

(a)

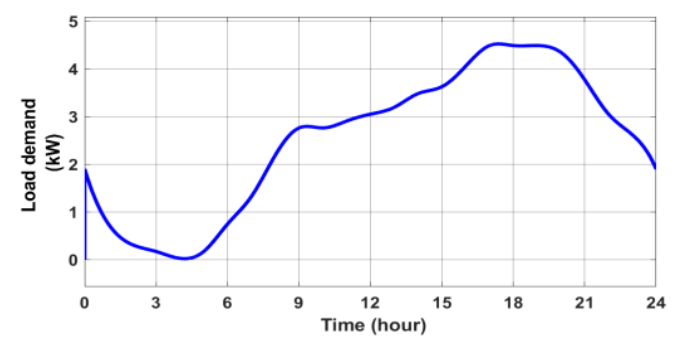

(b)

Fig. 2. Daily estimated power of (a) PV arrays (b) load demand.

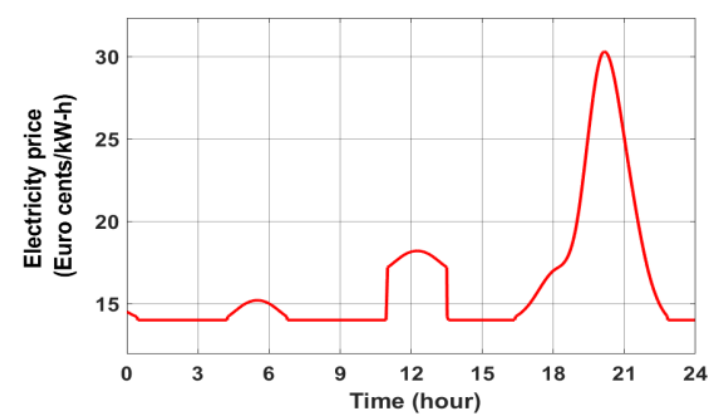

Fig. 3. Electricity price in a whole day (cents/kWh).

without losing generality, three different peaks are considered in the electricity price according to Fig. 3, and at other times, the price is almost constant.

As the last element in the system, there is the PEV, which plays a major role in smart charging algorithms due to its nature. In fact, because PEVs are parked for around 90 percent of their lifetime, controlling their charge and discharge can bring some benefits for various actors [14][15]. Actors include the user or owner of PEV, the charging station owner, and the grid operator. In this work, Renault Zoe R110 with the specifications provided in Table 1 is considered as one of the most popular electric vehicles in France. In the next section, the types of optimization algorithms, different objective functions, and selected types in this paper are briefly presented.

\section{BIDIRECTIONAL SMART CHARGING ALGORITHM}

In general, smart charging algorithms of PEVs are divided into two main categories, including rule-based methods [16][18] and optimization methods [19]-[24]. The rule-based algorithm, as its name implies, complies with defined rules that does not necessarily guarantee an optimal solution. Actually, due to the low computational volume and relatively high speed, this approach is usually employed as a complementary and real-time method to compensate for instantaneous errors. On the other hand, optimization algorithms are seeking available optimal solutions by considering objective functions and system constraints. However, heavy calculations and common uncertainties in the desired system indicate that it is necessary to use model 
predictive control (MPC) in parallel with optimization, which can deal with uncertainties well. There are several optimization methods in the literature such as linear, quadratic, nonlinear, dynamic, and robust. Obviously, the linear type is the simplest and fastest proposed optimization method in which all relations must be modeled linearly. In this regard, several studies have tried to use the linear optimization method even by approximating or simplifying nonlinear relationships [25], [26].

Also from another point of view, the general goal of smart charging can be different things such as reducing energy cost, power loss reduction, increasing the use of renewable energy sources, reducing load demand variations, and so on. Reducing the cost of energy exchanged with the grid is one of the most popular objective functions, which can be easily implemented with linear optimization. In this regard, the userfriendly linear programming algorithm, introduced by the authors in [19], is considered the main controller in this paper. As shown in Fig. 4, this algorithm is implemented as an MPCbased linear optimization that tries to charge the battery to the desired level $\left(\mathrm{SOC}_{\text {final }}\right)$ at the lowest cost. Three different scenarios are examined in the proposed algorithm, including uncontrolled, unidirectional, and bidirectional smart scenarios. However, due to the topic and the impossibility of battery discharging in uncontrolled and unidirectional scenarios, only the bidirectional scenario will be considered.

In summary, the bidirectional smart charging algorithm with linear optimization based on the predictive model is considered in this paper, which its objective function tries to reduce the cost of energy exchanged with the grid. The objective function and system constraints are optimized each 5-minute time step for a 20-hour time horizon. In the next section, the proposed linear technique for limiting the number of discharge cycles in the desired time horizon will be presented. It should be noted that due to the linearity of the smart charging algorithm, the new constraint should also be applied linearly.

\section{PROPOSED LINEAR TECHNIQUE}

In accordance with the MPC-based linear optimization method described in the previous section, the vehicle output power is predicted for the next 241 steps (20-hour time horizon by 5 -minute time step) in each step:

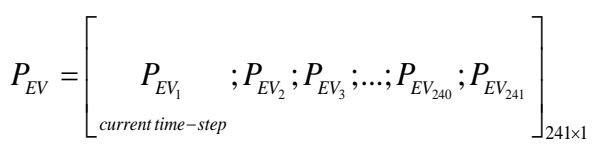

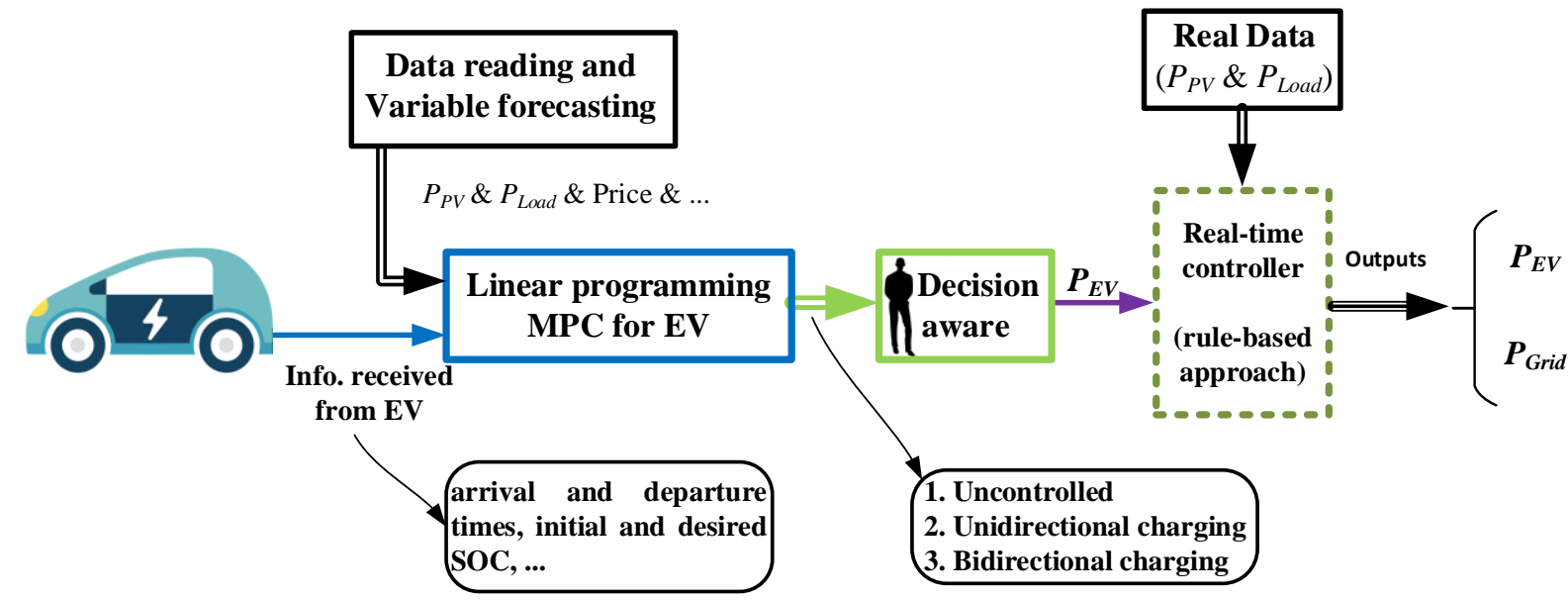

TABLE II

DIFFERENT VALUES OF THE TRANSITION VARIABLE

\begin{tabular}{|c|c|c|}
\hline $\mathrm{Si}_{\mathrm{i}-1}$ & $\begin{array}{c}\mathbf{0} \\
\text { (charge or neutral) }\end{array}$ & $\begin{array}{c}\mathbf{1} \\
\text { (discharge) }\end{array}$ \\
\hline $\begin{array}{c}\mathbf{0} \\
\text { (charge or neutral) }\end{array}$ & $\mathbf{0}-\mathbf{0}=\mathbf{0}$ & $\mathbf{1}-\mathbf{0}=\mathbf{1}$ \\
\hline $\begin{array}{c}\mathbf{1} \\
\text { (discharge) }\end{array}$ & $\mathbf{0}-\mathbf{1}=-\mathbf{1}$ & $\mathbf{1}-\mathbf{1}=\mathbf{0}$ \\
\hline
\end{tabular}

However, only the first element of the above matrix, i.e. $\mathrm{P}_{\mathrm{EV}}$, is applied to the system in the current step. For the next step, it is necessary to update the system information then optimizing the vehicle output power again in the desired time horizon. As explained, to keep the battery in a healthy situation, it should be possible to control the number of discharge cycles in this time horizon. In the rest of this section, the proposed linear technique for limiting the number of discharge cycles is presented. It should be noted that it is easily possible to implement this constraint nonlinearly, but the main purpose is to examine its linear implementation.

First of all, according to the defined power directions, the vehicle output power has positive values in discharging mode, and it has negative values in charging mode as well. Therefore, to count and limit the number of discharge cycles, it is necessary to distinguish positive values of power from other values. In other words, positive values are displayed with digit 1 , and negative or zero values are displayed with digit 0 . In this regard, the floating symbol variable $s$ with 241 elements is defined in binary form as relation (3).

$$
\begin{aligned}
& s=\text { optimvar('s ', N, 'Type ', 'integer ', } \\
& \text { 'LowerBound ', 0, 'UpperBound ',1) }
\end{aligned}
$$

where $\mathrm{N}$ represents the number of variable elements, and 'optimvar' function creates optimization variables. As it can be seen, due to the impossibility of using the binary format, the integer format with upper (1) and lower (0) bounds has been replaced. Now to convert the output power to the desired binary variable linearly, the two constraints are used as Equations (4) and (5).

$$
\begin{aligned}
& \text { optimprob.Constraints.s1 = optimconstr( } \mathrm{N}) \text {; } \\
& \text { for } i=1: 1: \mathrm{N} \\
& \text { optimprob.Constraints.s } 1(i)=P_{E V_{i}}-\left(P_{E V}^{\max } \times s_{i}\right) \leq 0 \text {; }
\end{aligned}
$$

Fig. 4. MPC-based linear optimization algorithm. 
optimprob.Constraints.s2 = optimconstr(N);

for $i=1: 1: \mathrm{N}$

optimprob.Constraints.s2 $(i)=-P_{E V_{i}}-\left(P_{E V}^{\max } \times\left(1-s_{i}\right)\right)<0$;

where $P_{E V}^{\max }$ indicates the maximum power of the vehicle, and 'optimconstr' function creates empty optimization constraint arrays. In Equation (4), first, $\mathrm{N}$ different constraints are defined for the whole time horizon. Then, with the help of the given inequality, the variable $s$ will be equal to 1 for the positive values of the vehicle output power. However, the variable is not specified for negative or zero values. In other words, it can be either 0 or 1 for those values. Therefore, Equation (5) is similarly employed to make the variable $s$ equal to zero when the vehicle power is negative or zero.

In reality, a small discharge does not have much effect on battery life. In addition, due to leakage current, the battery is being really discharged in neutral mode. Therefore, instead of zero, it is better to consider the parameter $\varepsilon$ to enter the discharge zone. In this paper, $\varepsilon$ is considered to be 50 watts. With these assumptions, Equations (4) and (5) are rewritten as follows:

optimprob.Constraints.s1 $(i)=P_{E V_{i}}-\left(\left(P_{E V}^{\max }-\varepsilon\right) \times s_{i}\right) \leq \varepsilon ;$

optimprob.Constraints.s $2(i)=-P_{E V_{i}}-\left(\left(P_{E V}^{\max }+\varepsilon\right) \times\left(1-s_{i}\right)\right) \leq-\varepsilon$;

So far, the discharge mode and other modes have been separated by the floating variable $s$. Next, by comparing the variable $s$ in each step $\left(s_{\mathrm{i}}\right)$ with its previous step $\left(s_{\mathrm{i}-1}\right)$, the starting point of the discharge mode can be identified. For this purpose, the variable $t$ is defined as follows.

$$
t_{i}=s_{i}-s_{i-1} ; i=2, \ldots, 241
$$

As it can be understood, the variable $t$ has only one element less than the variable $s$, and it may be equal to 0,1 , or -1 . According to Table II, the variable $t$ is equal to one, if and only if the state changes from the neutral or charging mode to the discharging mode.

It is also observed that the value of $t$ is equal to -1 when the discharge mode changes. Therefore, it is necessary to define a new slack variable with the help of equations similar to the previous equations, which is equal to 1 only in change to the discharge mode, and otherwise equal to 0 . In this regard, the discharge cycle variable $d c$ is defined as Equation (9).

$$
\begin{gathered}
d c=\text { optimvar('dc ', N-1, 'Type ', 'integer', } \\
\text { 'LowerBound ', 0, 'UpperBound ',1) }
\end{gathered}
$$

Using Equations (10) and (11) allows the variable $d c$ to be equal to 1 only when the value of $t$ is greater than 0.2 .

$$
\begin{aligned}
& \begin{array}{l}
\text { optimprob.Constraints.dc1 }=\text { optimconstr }(\mathrm{N}-1) ; \\
\text { for } i=2: 1: \mathrm{N} \\
\text { optimprob.Constraints.dc1 }(i)=t_{i}-\left((1-0.2) \times d c_{i-1}\right) \leq 0.2 ; \\
\text { optimprob.Constraints.dc2 }=\text { optimconstr }(\mathrm{N}-1) ; \\
\text { for } i=2: 1: \mathrm{N} \\
\text { optimprob.Constraints.dc2 }(i)=-t_{i}-\left(1.2 \times\left(1-d c_{i-1}\right)\right) \leq-0.2 ;
\end{array} \\
& \hline
\end{aligned}
$$

Finally, it is possible to detect the beginning of discharge cycles with the help of the $d c$ variable. However, if the vehicle is currently in the discharging mode, the $d c$ variable does not show it. So, the number of discharge cycles $N_{d c}$ can be obtained by Equation (12).

$$
N_{d c}=\sum_{1}^{N-1} d c+s_{1}
$$

To control the number of discharge cycles, the number $(x)$ must first be specified by the user or the system, then it is applied with the help of the following constraint.

$$
\begin{aligned}
& \text { optimprob.Constraints. } \mathrm{N}_{\mathrm{dc}}=\text { optimconstr(1); } \\
& \text { optimprob.Constraints. } \mathrm{N}_{\mathrm{dc}}(1)=N_{d c} \leq x
\end{aligned}
$$

In the next section, the control of the number of discharge cycles for different simulation scenarios is analyzed.

\section{SimUlation RESUltS}

In this section, the effectiveness of the proposed linear technique for limiting discharge cycles will be investigated for several values. In this regard, the simulation results of the smart charging control algorithm are presented in MATLAB/Simulink software in three different modes. For this purpose, a PEV is considered in accordance with the specifications presented in Table I. For simplicity and better understanding of the results, it is assumed that the vehicle with an initial charge of $60 \%$ arrives at the charging station at 3 o'clock in the morning. Also, based on the driver's order, this vehicle intends to leave at 22:30 with a final charge of $80 \%$.

In the first simulation, the smart charging controller is employed without the presence of the proposed linear technique, which its results are shown in Fig. 5. In this figure, the output power of various elements, the PEV output power, the PEV state of charge (SOC), and the cumulative cost of the energy exchanged with the grid are available. It should be noted that the local load demand has positive values, but it is presented as negative values due to its consumption
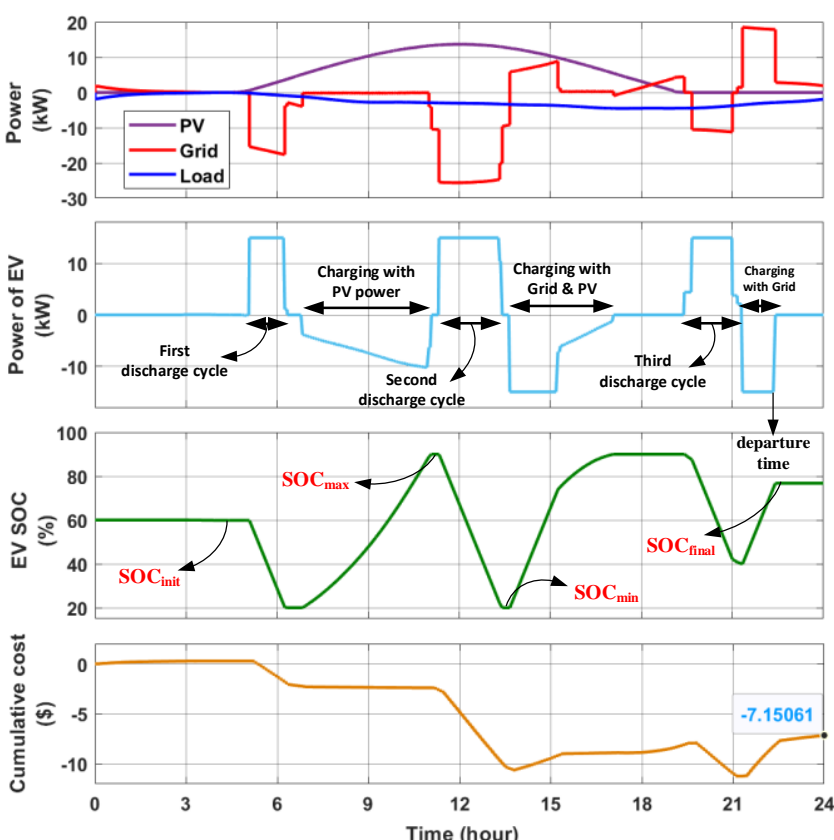

Fig. 5. Smart charging results without proposed linear technique. 

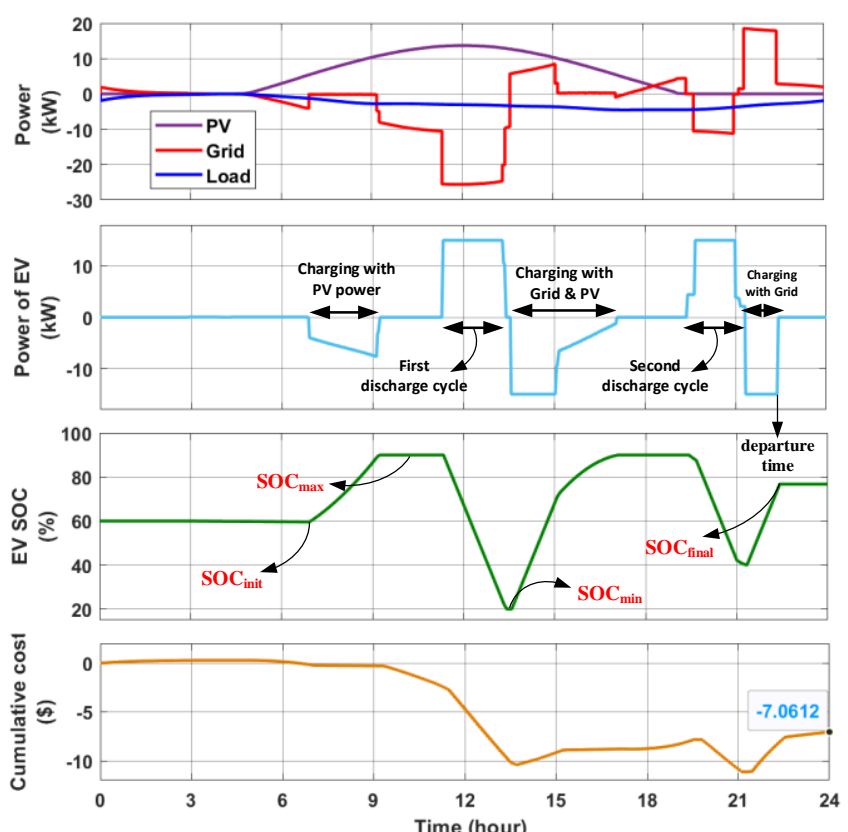

Fig. 6. Simulation results with proposed linear technique (two discharge cycles).

characteristic. Also, as mentioned, the output power of solar arrays is considered as predicted and without uncertainty. As it can be seen in Fig. 5, there are three discharge periods in the output power of PEV corresponding to different price peaks. In fact, in the first price peak (before 6 o'clock), the stored energy of PEV is used along with PV power production to inject into the grid and feeding the local load as well. Then, due to the minimum capacity of the battery and the electricity price reduction, the vehicle is fully charged with solar arrays between 7 and 11 o'clock. Also, due to the sufficient time and appropriate power range, the power exchanged with the grid is equal to zero in this period, so all the energy is spent on vehicle charging. At the second price peak (between 11 and 13 o'clock), all the energy stored in the battery is discharged again. After that, due to approaching the third price peak, the battery will be charged to the maximum capacity between 14 and 17. It should be noted that the grid also helps to charge the vehicle at the beginning of this period because of the limited time. Finally, at the third peak price, the energy stored in the vehicle is discharged to the extent that it can be recharged to the desired amount $\left(\mathrm{SOC}_{\text {final }}\right)$ at the time of departure. Therefore, it can be seen that the battery is charged to the desired value when leaving, and during this parking period, three discharge cycles are experienced. With these results, the charging station owner will receive $\$ 7.15$ from the grid at the end of the day. In the next scenarios, the number of discharge cycles can be reduced using the proposed technique, and the results can be presented for one and two cycles.

In the second scenario, the smart charging algorithm is implemented in the presence of the proposed linear technique assuming two discharge cycles, which its results are presented in Fig. 6. Again, PV output power and load profile are assumed to be constant. As it can be seen, the first discharge cycle corresponding to the first price peak is eliminated due to the added constraint. In other words, only two more profitable discharge cycles remain in the optimization. In fact, the optimization results only have been changed before the second price peak. Here, due to the desired limitation, the total cost received from the grid is slightly reduced, and instead, a lower discharge cycle is used.
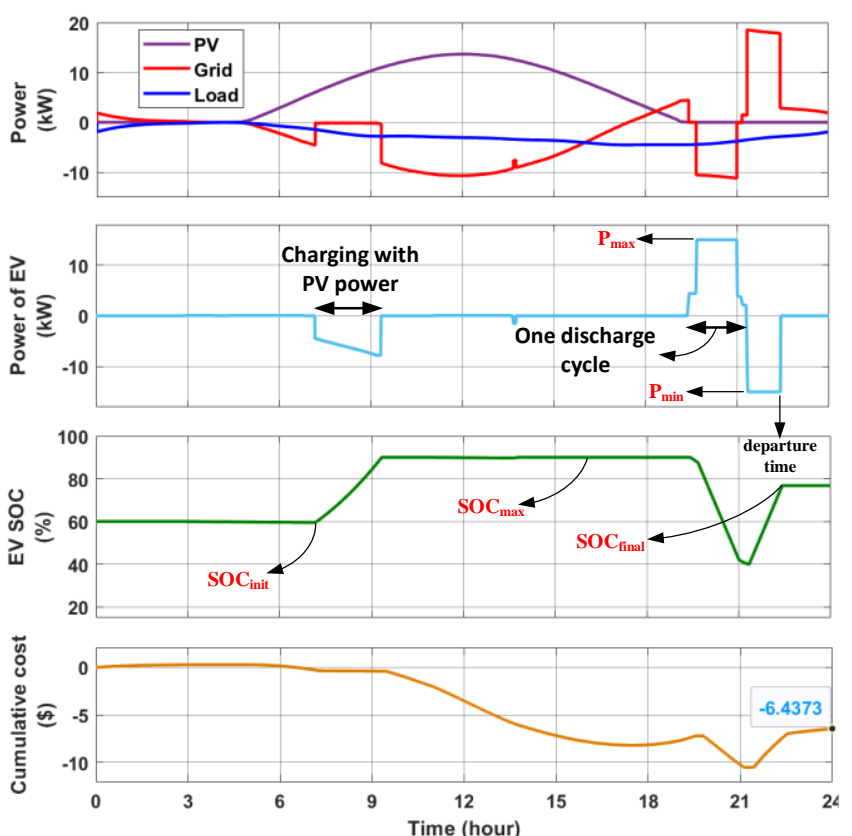

Fig. 7. Simulation results with proposed linear technique (one discharge cycle).

Finally, in the third scenario, the number of discharge cycles is considered equal to the minimum possible cycle, i.e. one cycle. The results related to this scenario are presented in Fig. 7. As expected, only the last price peak with higher values has remained in the optimization, and the other two discharge cycles are eliminated. At the same time, the total cost of energy has increased more than in previous scenarios. It is also clear that the optimization after the third price peak is similar to the previous scenarios because the constraint applied does not affect that time period.

As it was illustrated, the linear constraint on the number of discharge cycles is correctly satisfied in all scenarios, and the desired final SOC selected by the user is obtained.

\section{CONCLUSION}

In this paper, a novel linear technique was developed to control the number of discharge cycles in MPC-based optimization of PEVs. In fact, because of the importance of battery health, the user can contribute to the smart charging of the vehicle by specifying the number of discharge cycles during a whole day or during parking time. In this regard, the smart charging algorithm used along with the proposed technique select the most appropriate discharge cycles. It should be noted that it was possible to apply this limitation in other ways, but the linearity and simplicity of calculations can be mentioned as advantages of the proposed technique. In other words, the studied constraint was originally nonlinear, which was implemented as a linear problem using the proposed technique. For this purpose, a general structure of a PEV charging station assisted by PV arrays was introduced. Then, the effectiveness of the proposed technique was proved for different scenarios.

\section{REFERENCES}

M. Latifi, R. Sabzehgar, and M. Rasouli, "Reactive Power Compensation Using Plugged-In Electric Vehicles for an AC Power Grid," in IECON 2018 - 44th Annual Conference of the IEEE Industrial Electronics Society, 2018, pp. 4986-4991. 
[2] Y. Wang, S. Yue, and M. Pedram, "State-of-health aware optimal control of plug-in electric vehicles," in 2014 IEEE PES General Meeting | Conference \& Exposition, 2014, pp. $1-5$.

[3] W. Vermeer, G. R. Chandra Mouli, and P. Bauer, "RealTime Building Smart Charging System Based on PV Forecast and Li-Ion Battery Degradation," Energies, vol. 13, no. 13 , p. 3415 , Jul. 2020.

[4] A. Ovalle, A. Hably, and S. Bacha, "Escort evolutionary game dynamics application on a distribution system with $\mathrm{PV}$, BSS and EVs," in 2018 IEEE International Conference on Industrial Technology (ICIT), 2018, pp. 1690-1695.

[5] K. Hajar, B.Guo, A. Hably, and S. Bacha, "Smart charging impact on electric vehicles in presence of photovoltaics," in 2021 IEEE International Conference on Industrial Technology (ICIT), 2021, pp. 1-6.

[6] A. Ovalle, J. Fernandez, A. Hably, and S. Bacha, "An Electric Vehicle Load Management Application of the Mixed Strategist Dynamics and the Maximum Entropy Principle," IEEE Trans. Ind. Electron., vol. 63, no. 5, pp. 3060-3071, 2016.

[7] R. Fachrizal, M. Shepero, D. van der Meer, J. Munkhammar, and J. Widén, "Smart charging of electric vehicles considering photovoltaic power production and electricity consumption: A review," eTransportation, vol. 4, p. 100056, May 2020.

[8] L. Petrichenko, R. Petrichenko, and A. Sauhats, "The Choice of the Number of Charge/Discharge Cycles for a Battery Energy Storage System," in 2019 IEEE 60th International Scientific Conference on Power and Electrical Engineering of Riga Technical University (RTUCON), Oct. 2019, pp. 1-6.

[9] A. E. Trippe, R. Arunachala, T. Massier, A. Jossen, and T. Hamacher, "Charging optimization of battery electric vehicles including cycle battery aging," in IEEE PES Innovative Smart Grid Technologies, 2014, pp. 1-6.

[10] A. A. A. Al-Karakchi, G. Putrus, and R. Das, "Smart EV charging profiles to extend battery life," in $201752^{\text {nd }}$ International Universities Power Engineering Conference (UPEC), 2017, pp. 1-4.

[11] O. Kolawole, and I. Al-Anbagi, "The impact of EV battery cycle life on charge-discharge optimization in a V2G environment," in 2018 IEEE Power \& Energy Society Innovative Smart Grid Technologies Conference (ISGT), 2018, pp. 1-5.

[12] M. Yousefi, A. Hajizadeh, M. N. Soltani, and B. Hredzak, "Predictive Home Energy Management System With Photovoltaic Array, Heat Pump, and Plug-In Electric Vehicle," IEEE Trans. Ind. Informatics, vol. 17, no. 1, pp. 430-440, Jan. 2021.

[13] "https://www.enedis.fr/.".

[14] A. Ovalle, A. Hably, and S. Bacha, Grid Optimal Integration of Electric Vehicles: Examples with Matlab Implementation, vol. 137. Cham: Springer International Publishing, 2018.
[15] A. Ovalle, A. Hably, S. Bacha, and V. Pirsan, "Mixed strategist dynamics application to electrical vehicle distributed load scheduling," in IECON 2015 - 41st Annual Conference of the IEEE Industrial Electronics Society, 2015, pp. 3169-3174.

[16] H. Turker, A. Hably, and S. Bacha, "Smart Charging of Plug-In Hybrid Electric Vehicles (PHEVs) on the Residential Electric Grid Regarding the Voltage Plan," in 2013 IEEE International Electric Vehicle Conference (IEVC), 2013, pp. 1-6.

[17] R. Luthander, A. M. Nilsson, J. Widén, and M. Åberg, "Graphical analysis of photovoltaic generation and load matching in buildings: A novel way of studying selfconsumption and self-sufficiency," Appl. Energy, vol. 250, pp. 748-759, 2019.

[18] G. Barone, A. Buonomano, F. Calise, C. Forzano, and A. Palombo, "Building to vehicle to building concept toward a novel zero energy paradigm: Modelling and case studies," Renew. Sustain. Energy Rev., vol. 101, pp. 625-648, 2019.

[19] R. Razi, K. Hajar, A. Hably, and S. Bacha, "A UserFriendly Smart Charging Algorithm Based on EnergyAwareness for Different PEV Parking Scenarios," in 2021 $29^{\text {th }}$ Mediterranean Conference on Control and Automation (MED), 2021, pp. 1-6.

[20] C. Liu, K. Deng, G. Wen, and X. Yu, "Optimal Scheduling of Electric Vehicle Charging with Energy Storage Facility in Smart Grid," in IECON 2019 - 45th Annual Conference of the IEEE Industrial Electronics Society, 2019, vol. 1, pp. 6549-6554.

[21] H. Turker and S. Bacha, "Optimal Minimization of Plug-In Electric Vehicle Charging Cost With Vehicle-to-Home and Vehicle-to-Grid Concepts," IEEE Trans. Veh. Technol., vol. 67, no. 11, pp. 10281-10292, 2018.

[22] R. López-Rodríguez, A. Aguilera-González, I. Vechiu, and S. Bacha, "Day-Ahead MPC Energy Management System for an Island Wind/Storage Hybrid Power Plant," Energies, vol. 14 , no. 4. 2021.

[23] C. S. Ioakimidis, D. Thomas, P. Rycerski, and K. N. Genikomsakis, "Peak shaving and valley filling of power consumption profile in non-residential buildings using an electric vehicle parking lot," Energy, vol. 148, pp. 148158, 2018.

[24] D. Van Der Meer, G. R. C. Mouli, G. M. E. Mouli, L. R. Elizondo, and P. Bauer, "Energy Management System with PV Power Forecast to Optimally Charge EVs at the Workplace," IEEE Trans. Ind. Informatics, vol. 14, no. 1, pp. 311-320, 2018.

[25] O. Sundstrom and C. Binding, "Flexible Charging Optimization for Electric Vehicles Considering Distribution Grid Constraints," IEEE Trans. Smart Grid, vol. 3, no. 1, pp. 26-37, Mar. 2012.

[26] J. F. Franco, M. J. Rider, and R. Romero, “A Mixed-Integer Linear Programming Model for the Electric Vehicle Charging Coordination Problem in Unbalanced Electrical Distribution Systems," IEEE Trans. Smart Grid, vol. 6, no. 5, pp. 2200-2210, Sep. 2015. 